\title{
Evaluation of Anti-SARS-CoV-2 IgA in the Conjunctival Secretions of COVID-19 Patients
}

\author{
Hany Mahmoud (D) \\ Ahmed Hamody ${ }^{2}$ \\ Hesham M Hefny $\mathbb{D}^{3}$ \\ Dalia Tohamy $\mathbb{B D}^{4}$ \\ Islam Awny ${ }^{5}$ \\ 'Department of Ophthalmology, Faculty \\ of Medicine, Sohag University, Sohag, \\ Egypt; ${ }^{2}$ Anesthesia Department, Sohag \\ University, Sohag, Egypt; ${ }^{3}$ Clinical \\ Pathology Department, Sohag University, \\ Sohag, Egypt; ${ }^{4}$ Ophthalmology \\ Department, Assiut University, Assiut, \\ Egypt; ${ }^{5}$ Department of Ophthalmology, \\ Sohag University, Sohag, Egypt
}

Purpose: To assess the presence of anti-SARS-CoV-2 IgA in the conjunctival secretions of confirmed COVID-19 patients by nasopharyngeal swabs and correlate its presence with the severity of the disease, patient's age, sex and ocular symptoms.

Methods: This study included 44 positive COVID-19 patients confirmed with nasopharyngeal swabs during the period 17-28 February 2021 at Sohag Tropical Medicine Hospital. Tears and conjunctival secretions were examined for the presence of anti-SARS-CoV-2 IgA. Results: While non-reactive results are strongly correlated to low titre and vice versa, severity showed significant correlation with neither IgA reactivity nor titre. Meanwhile, IgA reactivity did not show significant correlation with either age or sex. The reactivity and IgA titre are correlated with ocular symptoms.

Conclusion: The anti-SARS-CoV-2 IgA could be found in ocular secretions in SARS-CoV -2 patients. There is no correlation with age or sex or severity of the disease; however, they are correlated with ocular symptoms.

Keywords: anti-SARS-CoV-2 IgA, ocular, secretions, swab

\section{Introduction}

Since the emergence of SARS-CoV-2 in China in 2019 and the WHO considering it to be a global emergency, ${ }^{1}$ many studies have evaluated its effects on the eyes, that is, ocular symptoms and signs such as follicular conjunctivitis, subconjunctival hemorrhage, eye congestion or retinal manifestations. ${ }^{2-5}$

Many studies have evaluated SARS-CoV-2 shedding in conjunctival tears and secretions. ${ }^{6,7}$ The presence of viral RNA was confirmed by many studies suggesting its transmission through the eyes. This could explain deaths amongst ophthalmologists and support the importance of safety measures when dealing with symptomatic and asymptomatic patients. Many ophthalmologists all over the world have been infected, which supports the suggestion that the virus sheds through tears, although we could not deny that the infection could occur also through breath or other routes. ${ }^{8-10}$ The American Academy of Ophthalmology (AAO) suspended all ophthalmological interventions except in urgent situations in March 2020, and many ophthalmological societies introduced protective measures such as social distancing in clinics, decreasing the number of patients examined, providing personal protective equipment (PPE) such as masks, gloves, face shields and slit-lamp breath shields, and conducting frequent sterilization. ${ }^{11}$ The use of $3 \mathrm{D}$ display systems could be a solution in both anterior and posterior segment surgeries.
Correspondence: Hany Mahmoud Department of Ophthalmology, Faculty of Medicine, Sohag University, Egypt Tel +20 1024368I II

Email drhanymahmoud@gmail.com 
Recently the pathogenesis of the virus was linked to Angiotensin Converting Enzyme 2 (ACE2) receptors, which could be found in many tissues including immune system cells. Many of these receptors were detected in conjunctival tissue, cornea, trabecular meshwork, limbal cells and many ocular tissues, and the spikes in the viral coat attached to these receptors causing the infection suggests their role in viral pathology and transmission. There are two suggested means of transmission: the flow of tears in nasolacrimal ducts to the respiratory system even in case of their obstruction and the tears flowing on the face reaching the nose and the blood flow from the eyes. $^{12-15}$

IgA is the mucosal response immunoglobulin and is produced in mucosal surfaces such as conjunctiva. Evaluation of its presence in conjunctival secretions could confirm the presence of the SARS-CoV-2 virus and the possibility of its transmission through the eyes. ${ }^{16-18}$

IgA could be the first immunology response to the coronavirus as it attacks the surfaces of the respiratory, gastrointestinal or ocular systems. It is the rapid immune response, its duration is short and it is the first line of defense locally, so we can suggest that it has a role to play in preventing the worsening of COVID-19 outcomes because it attacks the virus and decreases its load. ${ }^{18}$

The aim of this study was to evaluate the presence of IgA in conjunctival tears and secretions and correlate its presence with the symptomatology of SARS-CoV-2 in patients.

\section{Patients and Methods}

Forty-four COVID-19 patients confirmed by nasopharyngeal swab were enrolled in the study. They were recruited during the period 17-28 February 2021 from Sohag Tropical Medicine Hospital. All were subjected to an antiSARS-CoV-2 IgA test of their tears and conjunctival secretions.

Ocular manifestations including conjunctival, corneal, or retinal issues were examined using a portable slit-lamp and indirect ophthalmoscopy.

Inclusion criteria were all COVID-19 patients confirmed by nasopharyngeal swab attending Sohag Tropical Medicine Hospital during the period 17-28 February 2021.

There were no exclusion criteria.

\section{Ethical Consideration}

Ethical guidelines were followed and comprehensive written informed consent was taken from all patients involved in this study. Our study adhered to the tenets of the Declaration of Helsinki and the ethical board committees of our respective institutions (Sohag Faculty of Medicine, Assiut Faculty of medicine, Al-Shahid hospital-Sohag) granted approval.

\section{Method of Tear Collection}

On provision of informed consent and under total aseptic conditions and the wearing of PPE, tears were collected in the following manner:

- One drop of Proparacaine $0.5 \%$ was installed and the eye was closed for two minutes.

- For 30-60 seconds tears were collected from the lower fornix of the eye using a $2.0 \mathrm{~mm} \times 10.0 \mathrm{~mm}$ polyester fiber rod (Transorb Wick, Filtrona and Richmond, VA).

- The sample was put into a 1.5-mL Eppendorf tube.

\section{SARS-CoV-2 IgA Antibody by Chemiluminescent Immunoassay (CLIA) Method}

SARS-CoV-2 IgA antibody in tear samples was detected using an iFlash 3000 CLIA analyzer and YHLO-CLIA2019-nCoV IgA kits CATALOG \#: C86095A supplied by YHLO (Shenzhen Yhlo Biotech Co., Ltd., Shenzhen, China), according to the manufacturer's instructions. In the first incubation, Anti-2019-nCoV-2 IgA in the sample, sample diluent and 2019-nCoV antigen-coated paramagnetic microparticles reacted to form a complex, followed by washing in which the unbound materials were washed away from the solid phase in a magnetic field. In the second incubation, Acridinium-labeled anti-human IgA conjugate was added to form a reaction complex followed by another wash.

The pre-trigger and trigger solutions were added to the reaction mixture. The resulting chemiluminescent reaction was measured as relative light units (RLUs). A direct relationship exists between the amount of anti-2019nCoV-2 IgA in the sample and the RLUs detected by the iFlash optical system. Results were determined by comparing the RLU detected by the iFlash optical system with the cut-off calculated from 2019-nCoV IgA calibrators.

The antibody levels were expressed as $\mathrm{AU} / \mathrm{mL}$ and a nonreactive value was considered to be $<8.0 \mathrm{AU} / \mathrm{mL}$. A value range from $\geq 8$ to $<12 \mathrm{AU} / \mathrm{mL}$ was considered intermediate, while a value of $\geq 12.0 \mathrm{AU} / \mathrm{mL}$ was considered reactive.

We collected the data and recorded them. 


\section{Statistical Analysis}

Statistical analysis was done using IBM SPSS version 25 (IBM corporation, Chicago, USA, August 2017). Data was expressed as Mean \pm SD for quantitative data and numbers and percentages for qualitative data. Correlation was done by Spearman test; the strength of correlation was defined as negligible $(r<0.20)$, weak $(0.21<r<0.40)$, moderate $(0.41<r<0.70)$ or strong $(0.71<r<1)$.

\section{Results}

Using the Shapiro-Wilk test, the sample was normally distributed $(\mathrm{p}>0.05)$. The mean age of patients was $53.64 \pm 14.19(\operatorname{mean} \pm \mathrm{SD})$ and there were 26 males (26, $59.1 \%)$ and 18 females (40.9\%). Patient data is summarized in Tables 1 and 2 and Figure 1.

The correlation between the severity and presence of ocular symptoms and IgA titre is summarized in Table 3 and the correlations between $\operatorname{IgA}$ reactivity and both age and sex are summarized in Table 4. While non-reactive results are strongly correlated to low titre and vice versa, severity did not show a significant correlation with either IgA reactivity or titre. Moreover, the presence of ocular symptoms is strongly correlated with reactive results of IgA and moderately correlated with high $\operatorname{IgA}$ titre. Meanwhile, the presence of ocular symptoms did not show a significant correlation with the severity of general

Table I Participant Data

\begin{tabular}{|l|c|c|c|}
\hline \multicolumn{2}{|l|}{ Symptoms } & Frequency & $\%$ \\
\hline \multicolumn{2}{|l|}{ Dyspnea } & II & 25 \\
\hline Fever, Cough & 7 & 15.9 \\
\hline GIT & Stable & II & 25 \\
\hline Stability & Ventilator & 12 & 27.3 \\
\hline Ocular Symptoms & Yes & 13 & 29.5 \\
& No & 31 & 70.5 \\
\hline
\end{tabular}

Table 2 Results of IgA Detection and the Detection Titre

\begin{tabular}{|l|c|c|c|c|c|}
\hline Severity & $\begin{array}{c}\text { Reactive } \\
\text { n (\%) }\end{array}$ & $\begin{array}{c}\text { Intermediate } \\
\text { n (\%) }\end{array}$ & $\begin{array}{c}\text { Non-Reactive } \\
\text { n (\%) }\end{array}$ & $\begin{array}{c}\text { Total } \\
\text { n (\%) }\end{array}$ & $\begin{array}{c}\text { Titre } \\
\text { Mean } \pm \text { SD }\end{array}$ \\
\hline Mild & $8(36.4)$ & $1(4.5)$ & $13(59.1)$ & $22(50)$ & $13.85 \pm 21.40$ \\
Moderate & $4(40)$ & $0(0)$ & $6(60)$ & $10(22.7)$ & $10.43 \pm 11.63$ \\
Severe & $3(25)$ & $1(8.3)$ & $8(66.7)$ & $12(27.3)$ & $9.89 \pm 13.69$ \\
Total & $15(34.1)$ & $2(4.5)$ & $27(61.4)$ & $44(100)$ & \\
\hline
\end{tabular}


Table 3 Correlation Between Symptom Severity and IgA Titre

\begin{tabular}{|l|c|c|}
\hline & Result & Titre \\
\hline Ocular symptoms & $r=0.825(p<0.00 \mathrm{I})$ & $r=0.50(\mathrm{p}=0.00 \mathrm{I})$ \\
\hline Severity & $r=0.070(\mathrm{p}=0.65)$ & $r=0.072(\mathrm{p}=0.64)$ \\
\hline$r=0.237(p=0.12)$ & \multicolumn{2}{|c|}{$r=0.85(\mathrm{p}<0.00 \mathrm{I})$} \\
\hline
\end{tabular}

Table 4 Correlation Between IgA Reactivity and Age and Sex

\begin{tabular}{|l|c|c|}
\hline & Age & Sex \\
\hline Result & $r=-0.15(p=0.92)$ & $r=0.054(p=0.73)$ \\
\hline
\end{tabular}

flowing on the face could carry the virus with $\operatorname{IgA}$ to the mucous membranes of the respiratory system. ${ }^{21}$

A non-significant correlation was found between severity of symptoms and IgA titre, which suggests that even mild cases could shed the virus and be a source of infection. $^{22}$ IgA could be secreted regardless of the presence of ocular symptoms.

This study showed that ocular symptoms are strongly correlated with reactive results of IgA and moderately correlated with high IgA titre. Meanwhile, the presence of ocular symptoms did not show significant correlation with the severity of general symptoms. This differs from other studies that show no correlation. ${ }^{20}$ This can be explained by the idea that ocular symptoms could occur as an immune response and become more evident when there is a greater immune response in the form of virus/IgA interaction. Confirmation of this explanation requires further investigation. On the other hand, IgA reactivity did not show a significant correlation with either age or sex, a finding demonstrated in many previous studies.

Conjunctival tissue is an optimal site for virus replication and so the conjunctival route of infection should be confirmed as leading to the infection and even death of ophthalmologists. $^{6}$

\section{Limitations and Recommendations}

The limitations of this study were its small sample size and the small number of previous studies regarding the presence of IgA in tears. We recommend conducting further studies with a larger number of participants.

\section{Acknowledgment}

This is to certify that the article has not been presented in a meeting.

\section{Funding}

This is to certify that the authors did not receive any financial support from any public or private sources.

\section{Disclosure}

The authors reported no conflicts of interest for this work and no financial or proprietary interest in the product, method, or material described herein.

\section{References}

1. Sohrabi C, Alsafi Z, O'Neill N, et al. World Health Organization declares global emergency: a review of the 2019 novel coronavirus (COVID-19). Int J Surg. 2020;76:71-76. doi:10.1016/j.ijsu.2020.02.034

2. Rousseau A, Fenolland JR, Labetoulle M. SARS-CoV-2, COVID-19 et œil: le point sur les données publiées [SARS-CoV-2, COVID-19 and the eye: an update on published data]. J Fr Ophtalmol. 2020;43 (7):642-652. French. doi:10.1016/j.jfo.2020.05.003

3. Wu P, Duan F, Luo C, et al. Characteristics of ocular findings of patients with coronavirus disease 2019 (COVID-19) in Hubei Province, China. JAMA Ophthalmol. 2020;138(5):575-578. doi:10.1001/jamaophthalmol.2020.1291

4. Barton LM, Duval EJ, Stroberg E, et al. COVID-19 autopsies, Oklahoma, USA. Am J Clin Pathol. 2020;153(6):725-733. doi:10.1093/ajcp/aqaa062

5. Bertoli F, Veritti D, Danese C, et al. Ocular findings in COVID-19 patients: a review of direct manifestations and indirect effects on the eye. J Ophthalmol. 2020;2020:4827304. doi:10.1155/2020/4827304

6. Xia J, Tong J, Liu M, et al. Evaluation of coronavirus in tears and conjunctival secretions of patients with SARS-CoV-2 infection. J Med Virol. 2020;92(6):589-594. doi:10.1002/jmv.25725

7. Mahmoud H, Ammar H, El Rashidy A, et al. Assessment of coronavirus in the conjunctival tears and secretions in patients with SARS-CoV-2 infection in Sohag Province, Egypt. Clin Ophthalmol. 2020;14:2701-2708. doi:10.2147/OPTH.S270006

8. Qing H, Li Z, Yang Z, et al. The possibility of COVID-19 transmission from eye to nose. Acta Ophthalmol. 2020;98(3):e388. doi:10.1111/aos.14412

9. Hoenig LJ. The eye and COVID-19 pandemic. Clin Dermatol. 2020;38(4):506. doi:10.1016/j.clindermatol.2020.03.013

10. Dockery DM, Rowe SG, Murphy MA, et al. The ocular manifestations and transmission of COVID-19: recommendations for prevention. $J$ Emerg Med. 2020;59(1):137-140. doi:10.1016/j. jemermed.2020.04.060

11. Napoli PE, Nioi M, d'Aloja E, Fossarello M. Safety recommendations and medical liability in ocular surgery during the COVID-19 pandemic: an unsolved dilemma. J Clin Med. 2020;9(5):1403. doi: $10.3390 / \mathrm{jcm} 9051403$

12. Peng M, Dai J, Sugali CK, Rayana NP, Mao W. The role of the ocular tissue in SARS-CoV-2 transmission. Clin Ophthalmol. 2020;14:3017-3024. doi:10.2147/OPTH.S269868

13. Hikmet F, Méar L, Edvinsson $\AA$, et al. The protein expression profile of ACE2 in human tissues. Mol Syst Biol. 2020;16(7):e9610. doi: $10.15252 / \mathrm{msb} .20209610$

14. Pham TL, He J, Kakazu AH, et al. Elovanoid-N32 or RvD6-isomer decrease ACE2 and binding of S protein RBD after injury or INF $\gamma$ in the eye. Res Sq [Preprint]. 2020:rs.3.rs-55764. doi:10.21203/rs.3.rs55764/v1

15. Napoli PE, Nioi M, d'Aloja E, Fossarello M. The ocular surface and the coronavirus disease 2019: does a dual 'ocular route' exist? J Clin Med. 2020;9(5):1269. doi:10.3390/jcm9051269

16. Knop N, Knop E. Conjunctiva-associated lymphoid tissue in the human eye. Invest Ophthalmol Vis Sci. 2000;41(6):1270-1279. 
17. Kugadas A, Wright Q, Geddes-McAlister J, et al. Role of microbiota in strengthening ocular mucosal barrier function through secretory IgA. Invest Ophthalmol Vis Sci. 2017;58(11):4593-4600. doi:10.1167/iovs.17-22119

18. van Ginkel FW, Gulley SL, Lammers A, et al. Conjunctiva-associated lymphoid tissue in avian mucosal immunity. Dev Comp Immunol. 2012;36(2):289-297. doi:10.1016/j.dci.2011.04.012

19. Napoli PE, Mangoni L, Gentile P, Braghiroli M, Fossarello M. A panel of broad-spectrum antivirals in topical ophthalmic medications from the drug repurposing approach during and after the coronavirus disease 2019 era. J Clin Med. 2020;9(8):2441. doi:10.3390/ jem9082441

20. Caselli E, Soffritti I, Lamberti G, et al. Anti-SARS-Cov-2 IgA response in tears of COVID-19 patients. Biology. 2020;9(11):374. doi:10.3390/biology9110374
21. Napoli PE, Nioi M, Mangoni L, et al. Fourier-domain OCT imaging of the ocular surface and tear film dynamics: a review of the state of the art and an integrative model of the tear behavior during the inter-blink period and visual fixation. J Clin Med. 2020;9(3):668. doi: $10.3390 / \mathrm{jcm} 9030668$

22. Cervia C, Nilsson J, Zurbuchen Y, et al. Systemic and mucosal antibody responses specific to SARS-CoV-2 during mild versus severe COVID-19. J Allergy Clin Immunol. 2021;147(2):545-557. e9. doi:10.1016/j.jaci.2020.10.040
Clinical Ophthalmology

\section{Publish your work in this journal}

Clinical Ophthalmology is an international, peer-reviewed journal covering all subspecialties within ophthalmology. Key topics include: Optometry; Visual science; Pharmacology and drug therapy in eye diseases; Basic Sciences; Primary and Secondary eye care; Patient Safety and Quality of Care Improvements. This journal is indexed on PubMed

Submit your manuscript here: https://www.dovepress.com/clinical-ophthalmology-journal
Dovepress

Central and CAS, and is the official journal of The Society of Clinical Ophthalmology (SCO). The manuscript management system is completely online and includes a very quick and fair peer-review system, which is all easy to use. Visit http://www.dovepress.com/ testimonials.php to read real quotes from published authors. 